\title{
Project Scheduling Tools and Techniques for Effective Construction Management
}

\author{
Opeyemi Isaac-Laughter, Ogunnubi Titilope, Orimoloye Moyinolorun, Abraham Ayomide, Ukwunna Chiamaka \\ Department of Architecture \\ Covenant University \\ Canaanland, Ota, Ogun State, Nigeria \\ Email Address: isaac-laughter.opeyemi@stu.cu.edu.ng \\ Phone Number: +2348172798291
}

\begin{abstract}
Project scheduling has identified as a key aspect in the planning of any construction project. Any construction project that is to run smoothly needs to have a time-based plan of events for efficient resource allocation and effective project delivery. Project managers use a variety of tools and techniques to develop, monitor, and control project schedules. This paper seeks to examine project scheduling tools used in building construction project management in order to identify key methodologies employed towards achieving a sustainable construction management process. The use of literature review as a data collection tool will aid in achieving the aim of the research. This study expects to provide valuable information and guidelines for how and when to use these tools, putting the concept of project scheduling in construction management within the local context. This research will be used to learn about the requirements and restrictions that accompany the use of project scheduling tools and to learn about the similarities and differences between these tools. This research also generally seeks help students and researchers by adding to the body of knowledge on these project scheduling tools and provide guidelines for the use of these tools in order to achieve efficiency. The beneficiaries of this research project will be project managers, contractors, clients and other professionals in the building industry.
\end{abstract}

Keywords: Efficiency, Project Delivery, Construction Management \& Scheduling.

iSTEAMS Proceedings Reference Format

Opeyemi, I., Ogunnubi, T, Orimoloye, M, Abraham, A. \& Ukwunna, C. (2019): Project Scheduling Tools and Techniques for Effective Construction Management. Proceedings of the $15^{\text {th }}$ iSTEAMS Research Nexus Conference, Chrisland University, Abeokuta, Nigeria, $16^{\text {th }}-18^{\text {th }}$ April, 2019. Pp 321-338. www.isteams.net DOI Affix - https://doi.org/ 10.22624/AIMS/iSTEAMS-2019/N15N1P29

\section{BACKGROUND TO THE STUDY}

Before construction management can be defined, the word management has to be defined. Management deals with the use of limited resources combined with forecasting, planning leadership and execution skills to accomplish predetermined precise goals (Ruina, 2015). Construction management deals with economical consumption of the resources available in the least possible time for successful completion of construction project. Resources in construction management include men, materials, machinery, time and money. Construction management seeks to get the construction work completed within the estimated budget and time specified, help to maintain a reputation for high quality workmanship, help make sound decisions and to develop an organizational structure that encourages teamwork (Mishra, 2018). Project scheduling is a key function of construction management, alongside project planning, organizing, staffing, directing, controlling and coordinating. Project planning deals with selecting a particular method and the order of work to be adopted for a project from all the possible ways and sequences in which it could be done; organizing deals with dividing of the total construction work into manageable departments/sections and systematically managing various operations by delegating specific tasks to individuals; staffing is concerned with the provision of right 
people to each section/department created for successful completion of a construction project; directing deals with training subordinates to carryout assigned tasks, supervising their work and guiding and motivating them; controlling involves a constant review of the work plan to check on actual achievements and to discover and rectify deviation through appropriate corrective measures; coordinating involves bringing together and coordinating the work of various departments and sections so as to have good communication (Mishra, 2018).

Scheduling in project management deals with the arrangement, control and optimization of work to be done in a manufacturing or construction process. It is a process that enables the effective and efficient allocation of resources and materials in a construction project. According to Ssempebwa (2013), There are two types of scheduling; forward scheduling and backward scheduling. "Forward scheduling is planning the tasks from the date resources become available to determine the shipping date or the due date while backward scheduling is planning the tasks from the due date or required-by date to determine the start date and/or any changes in capacity required." A schedule in project management is usually considered as a list of activities, milestones and deliverables, that estimates the timeframe for commencement and conclusion, using key information such as the resources allocated, the duration of individual tasks, the budget and the relationship between tasks that are reliant on other activities (Ghaeli \& Sadi-Nezhad, 2019).

\section{STATEMENT OF PROBLEM}

Producing and managing a construction project schedule can be a challenge for many construction business owners. In order to be effective, the construction project schedule must be both accurate for the short-term and flexible for the long-term (Van Dyke, 2019). Scheduling is a key part of the project planning process and it is therefore important to the final outcome of the project. Elements on a schedule are associated with different issues such as the work breakdown structure (WBS) terminal elements and the statement of work. The object of project scheduling and management is to produce a complete project by considering the client's desires. In more than a few cases, the primary object of project management is to change the client's brief to address the client's objectives. When the client's targets become transparent, they ought to influence all decisions made by other parties involved in the project such as project managers, designers and contractors (Ghaeli \& Sadi-Nezhad, 2019). The schedule defines the sequence and method in which the materials will be put in place. Thus, the earlier the schedule is put on paper (or computer screen, tablet, etc.) and communicated to the project team, the better (Fournier, 2015).

\section{OBJECTIVE}

The main objective of this study is to examine project scheduling tools used in building construction project management in order to identify key methodologies employed towards achieving a sustainable construction management process.

\section{METHODOLOGY}

Due to the exploratory nature of the research, the research will be purely approached qualitatively, with literature review as the main means of data collection. Information will be gathered from academic, literary and internet sources. The literature studied will be about the below listed scheduling techniques;

1. Gantt Chart

2. Milestone Chart

3. Line of Balance

4. $\quad$ Network Scheduling (CPM, PERT) 


\section{DATA PRESENTATION}

\subsection{Results and Findings (Project Scheduling Techniques)}

\subsubsection{Gantt Charts}

\section{History}

Gantt charts first came about in the late $19^{\text {th }}$ century as the Harmonogram, created by Karol Adamiecki, an engineer from Poland who had an interest in management techniques and ideas. Adamiecki came up with the concept of visually displaying processes so as to make production scheduling easier. Due to the Harmonogram being in the polish language only, it had limited exposure. Fifteen years after Adamiacki's chart, Henry Gantt, also an engineer, formulated his own chart which was the basis for what is known as the Gantt chart today. (Gantt.com, 2019; TeamGantt, 2019).

\section{Definition}

A Gantt chart can be defined as "a visual view of tasks scheduled over time." It is used for planning different types of projects as it serves as an efficient way of displaying tasks to be executed per day while also aiding with viewing in commencement and conclusion dates of project (ProjectManager.com Inc., 2019). Van Dyke (2019) defines the Gantt chart as a chart that displays the breakdown of the workflow of a project on the y-axis, with the timeframe for the completion of the tasks/phases of the project displayed on the x-axis. The time it would take to complete the tasks/phases of the project are displayed as bars, with the shading of the bars as an indication of progress as shown in figure 5.1 below.

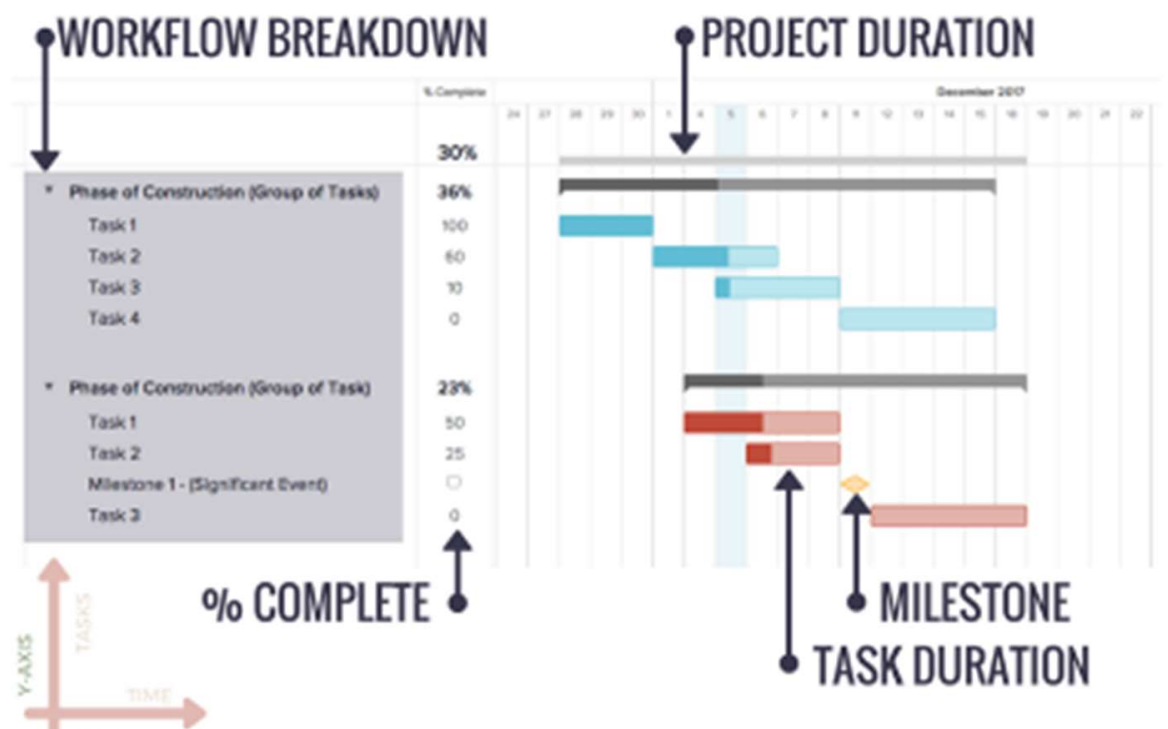

Figure 5.1: Basic layout of a Gantt chart

Source: Van Dyke (2019)

As shown in figure 5.1, a Gantt chart indicates the following: the various tasks to be done, the start and end times of the individual tasks, the duration of each task, the points where different tasks overlap (with how much they overlap) and milestone points in a project. 


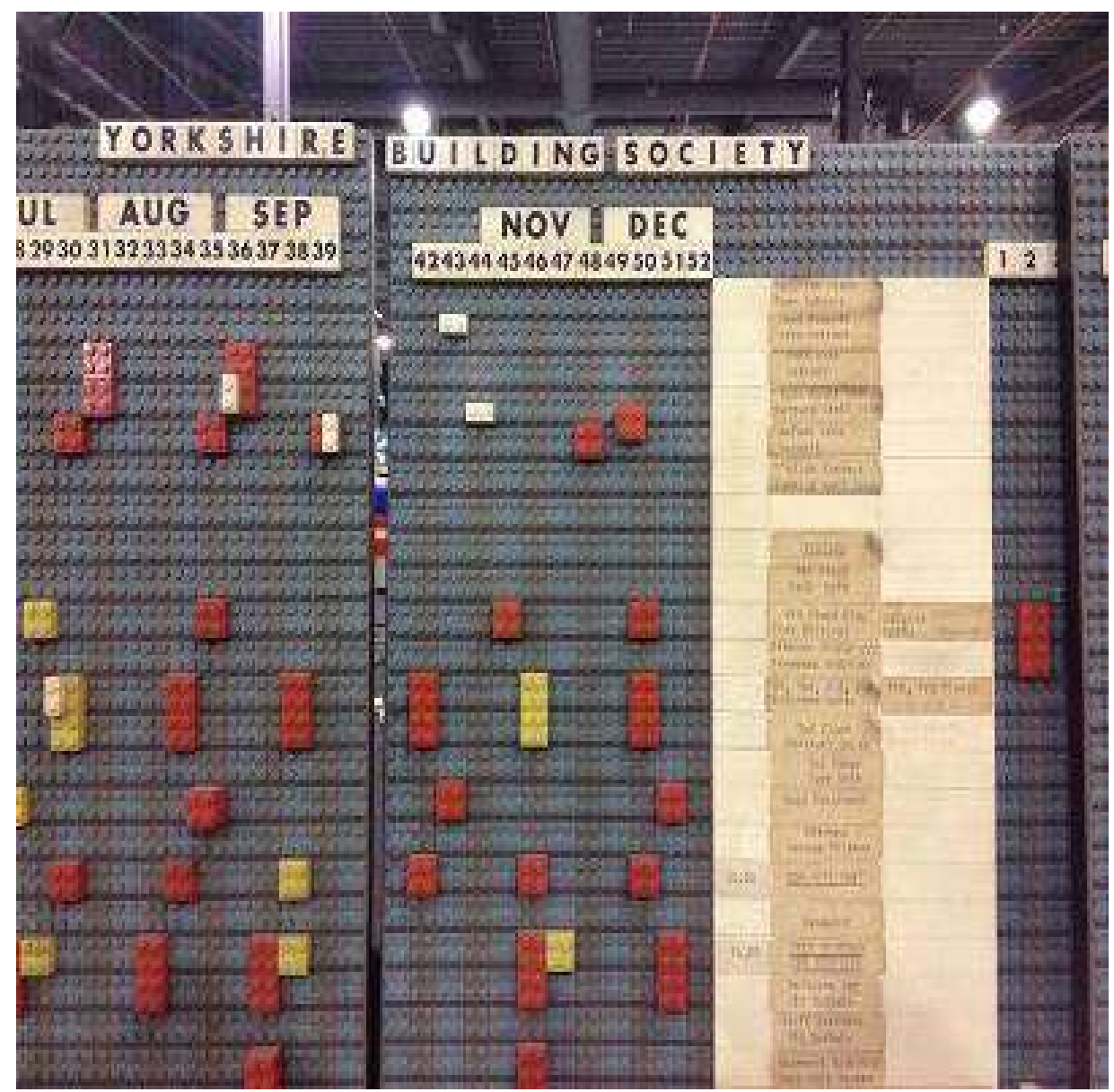

Figure 5.2: A Lego ${ }^{\mathrm{TM}}$ Gantt chart

Source: ProjectManager.com Inc. (2019)

Gantt charts were originally created manually as shown in the chart in figure 5.2, which was a labor-intensive process. Lego ${ }^{\text {TM }}$ blocks where common tools used in projects to create Gantt charts. This ensured changes that were made to the project necessitated recreating the chart and this was not a practical and efficient approach. The advent of computers and software enabled the ease of creation and management of these charts which made for efficiency. Many industries such as construction, manufacturing, event planning and software development make use of Gantt charts in the planning, scheduling and execution of their projects.

\subsubsection{Milestone Charts}

According to Manning (2018a), a milestine chart is such that places a focus on "planned significant events cheduled to take place at specific times" during the project. The significant events focused on could be the commencement or completion of an activity that is critical to the project, dates of approval, delivery of equipment and material acquisition dates. Milestone charts provides information concerning the project schedule by making use of symbols imposed on a calendar. Although there are no standards set for the symbols used, table 5.1 below shows examples of symbols recommended for milestone charts. 
Table 5.1: Examples of Milestone Chart Symbols

\begin{tabular}{|c|c|}
\hline Basic Symbol & Meaning \\
\hline & Schedule Completion \\
\hline & Actual Completion \\
\hline & Previous Scheduled Completion - Still in Future \\
\hline & Previous Scheduled Completion - Date Passed \\
\hline Representative Uses & Meaning \\
\hline & Anticipated Slip - Rescheduled Completion \\
\hline & Actual Slip - Rescheduled Completion \\
\hline & Actual Slip - Actual Completion \\
\hline & Actual Completion Ahead of Schedule \\
\hline & Time Span Action \\
\hline 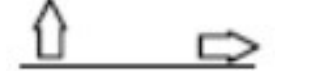 & Continuous Action \\
\hline
\end{tabular}

Milestone charts can be integrated into Gantt charts as shown on figure 5.3. These charts are known as combination charts and they serve as an effective and simple way of monitoring and controlling projects (Defense System Management College, 2001). 


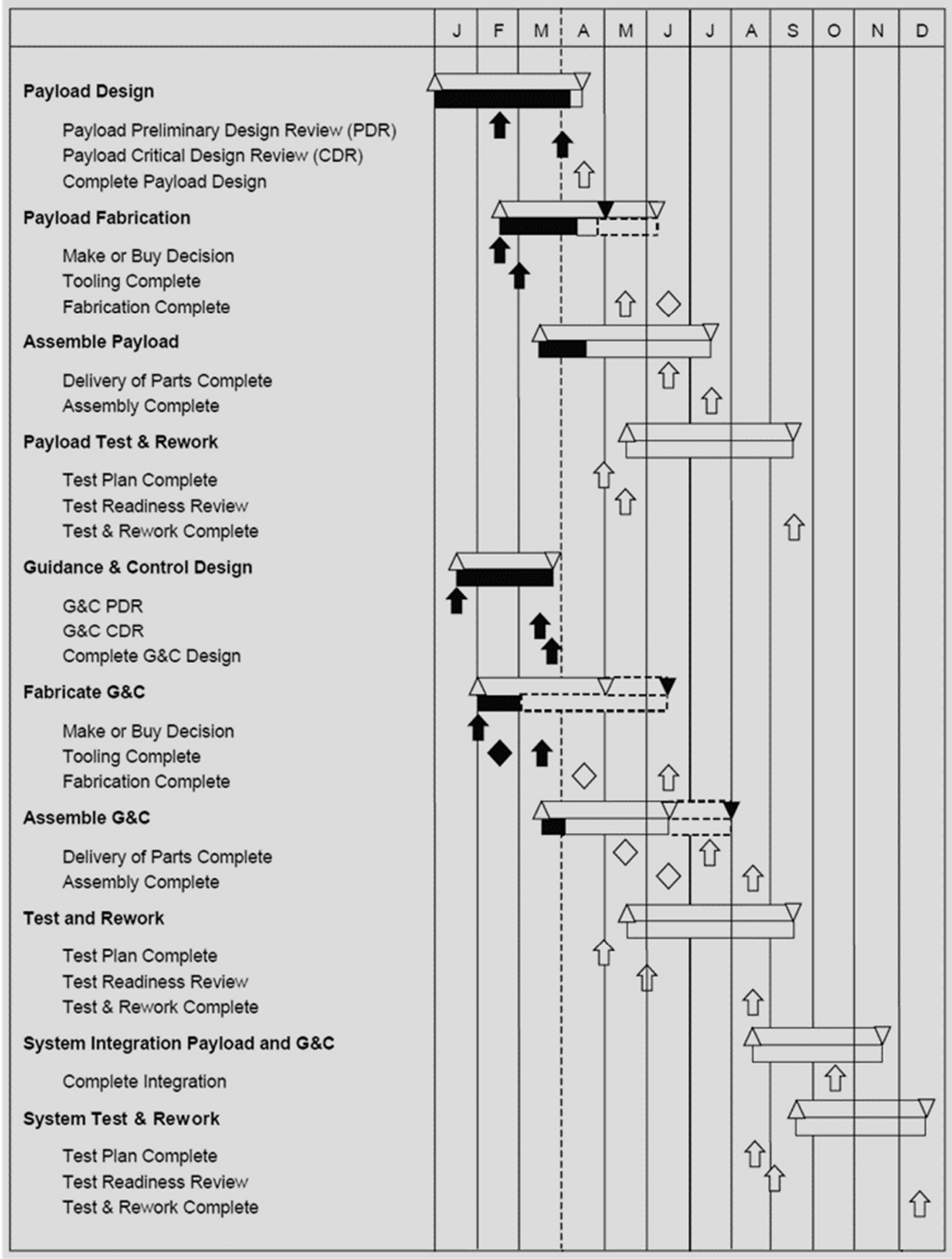

Figure 5.3: An example of a combination chart

Source: Defense System Management College (2001) 


\subsubsection{Advantages and Disadvantages of Milestone and Gantt Charts}

Making use of these charts comes with various advantages and disadvantages which are presented in table 5.2 below.

Table 5.2: Advantages and Disadvantages of Milestone and Gantt Charts

\begin{tabular}{|c|c|c|}
\hline $\mathrm{S} / \mathrm{N}$ & Advantages & Disadvantages \\
\hline 1. & These charts are simple to create and update. & Schedule analysis can not be done in detail. \\
\hline 2. & $\begin{array}{l}\text { These charts help to visualize the project in its } \\
\text { entirety by providing a "start-to-finish view" of the } \\
\text { timeline of the project. }\end{array}$ & $\begin{array}{l}\text { They can become very complex, especially for big } \\
\text { projects. }\end{array}$ \\
\hline 3. & $\begin{array}{l}\text { These charts are relatively cheap to prepare with } \\
\text { the use of software. }\end{array}$ & $\begin{array}{l}\text { The effects of early or late execution of tasks is not } \\
\text { shown. }\end{array}$ \\
\hline 4. & $\begin{array}{l}\text { These charts ensure effective collaboration } \\
\text { among the executors of the tasks. }\end{array}$ & $\begin{array}{l}\text { The amount of work to do is not accurately } \\
\text { represented by the bars. }\end{array}$ \\
\hline 5. & $\begin{array}{l}\text { These charts easily link calendar dates to } \\
\text { activities. }\end{array}$ & $\begin{array}{l}\text { Dependencies among activities are not accurately } \\
\text { represented, especially in large projects. }\end{array}$ \\
\hline 6. & $\begin{array}{l}\text { These charts serve as the entry point to more } \\
\text { complex scheduling. }\end{array}$ & There is a need for constant updating. \\
\hline 7. & $\begin{array}{l}\text { These charts help develop estimates that are } \\
\text { reliable especially when the work is repetitive in } \\
\text { nature. }\end{array}$ & $\begin{array}{l}\text { These charts do not indicate the level of reliability of } \\
\text { the estimates. }\end{array}$ \\
\hline 8. & These charts help set realistic timelines. & $\begin{array}{l}\text { Risky activities and uncertainties are not accounted } \\
\text { for. }\end{array}$ \\
\hline 9. & These charts are easy to summarize. & $\begin{array}{l}\text { Consequences of alternative actions cannot be easily } \\
\text { explored. }\end{array}$ \\
\hline
\end{tabular}

In instances when information presented needs to be concise and efficient, these charts serve as good tools for communicating with persons in managerial roles, due to the simplicity of the charts and the ease to which they can be interpreted (Defense System Management College, 2001).

\subsection{Line of Balance (LOB)}

\section{History}

The Line of Balance was developed by a group of professionals led by George E. Fouch. The Goodyear Tire and Rubber Company in 1941 made use of it in the monitoring of their production processes and it was also successfully utilized by defence suppliers during World War II for the mobilization program of the United States Navy (Valuation Opinions, Inc., 2018). The Line of Balance was eventually developed for production control, industrial manufacturing and applications in the construction industry (Designing Buildings Wiki, 2017).

\section{Definition}

Line of balance (also known as Elemental Trend Analysis) is a way of representing work that is to be repeated in a project, usually as a single line on a graph. The rate of expected progress that has to be made to be in line with the project schedule is also represented. Manning (2018b) describes a line of balance as a "management control process for collecting, measuring and presenting facts relating to time, cost and accomplishment - all measured against a specific plan." 
The status, timing, background and phasing of the project's activities are shown to provide the project management team with tools that measure to help:

i. $\quad$ Compare the current project's status and progress with a formal objective plan

ii. Examine the deviations from the plans already established while also assessing the impact of the deviations on the remaining project activities.

iii. Receive timely information on areas that are problematic, indicating the areas that corrections are needed.

iv. Forecast future performance.

"A Line of Balance diagram shows the repetitive project work as a single line on a graph. It differs from a bar chart which shows a particular activity's duration, by showing the rate at which the work has to be undertaken to stay on schedule, as well as the relationship of one trade or process to the subsequent trade or process." "The project timeline is represented along the $x$-axis of the graph while the work areas that define the project are represented along the $y$ axis" (Designing Buildings Wiki, 2017; Manning, Line of Balance (LOB), 2018; Praxis, 2015; Mosaic Projects, 2019). This is shown in figure 5.4 below.

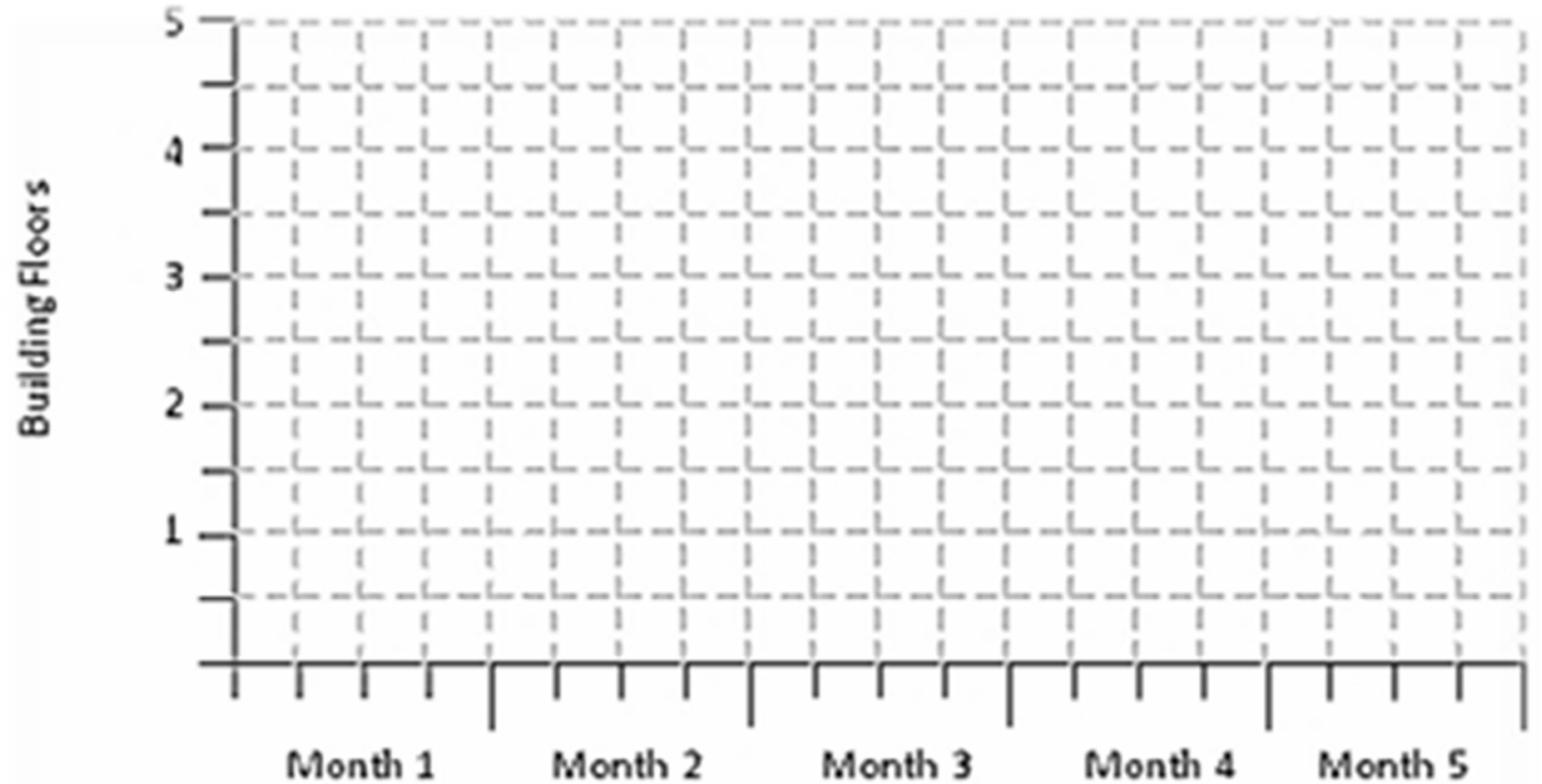

\section{Project Duration (Months)}

Figure 5.4: A typical Line of Balance diagram

Source: Designing Buildings Wiki (2017)

\section{Uses}

Praxis (2015) describes the Line of Balance as a time scheduling technique that is used typically in scenerios where "skilled resources are performing the same activity on multiple products within a project." Figure 5.5 shows an example of the use of the Line of Balance for a residential project. 


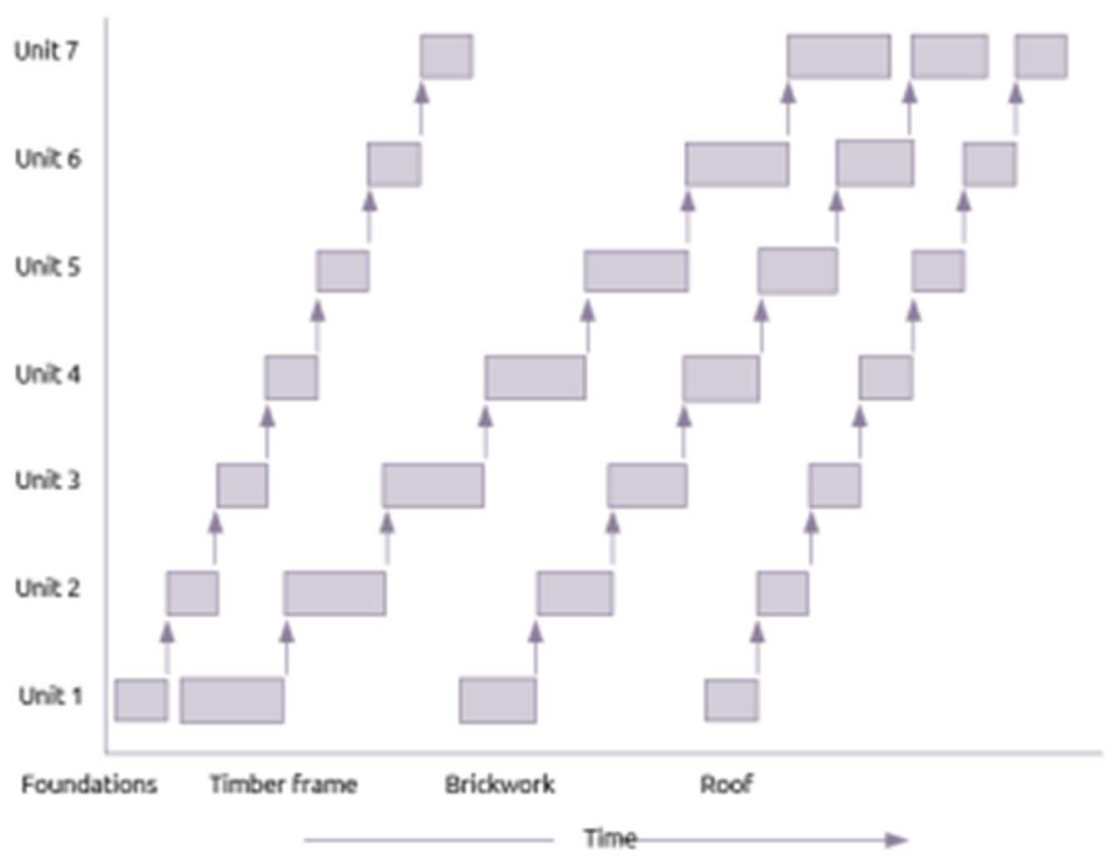

Figure 5.5: A basic Line of Balance diagram for a residential project Source: Praxis (2015)

According to figure 5.5, the residential project involves seven (7) housing units with four (4) teams of workers, with each team attached to specific phases of the project. This diagram indicates that each team has to work sequentially, which os not the most efficient way of working. "It is much more efficient to schedule the work so that there is only one team of workers on site and that team has continuity of work from start to finish." This is represented in figure 5.6 below.

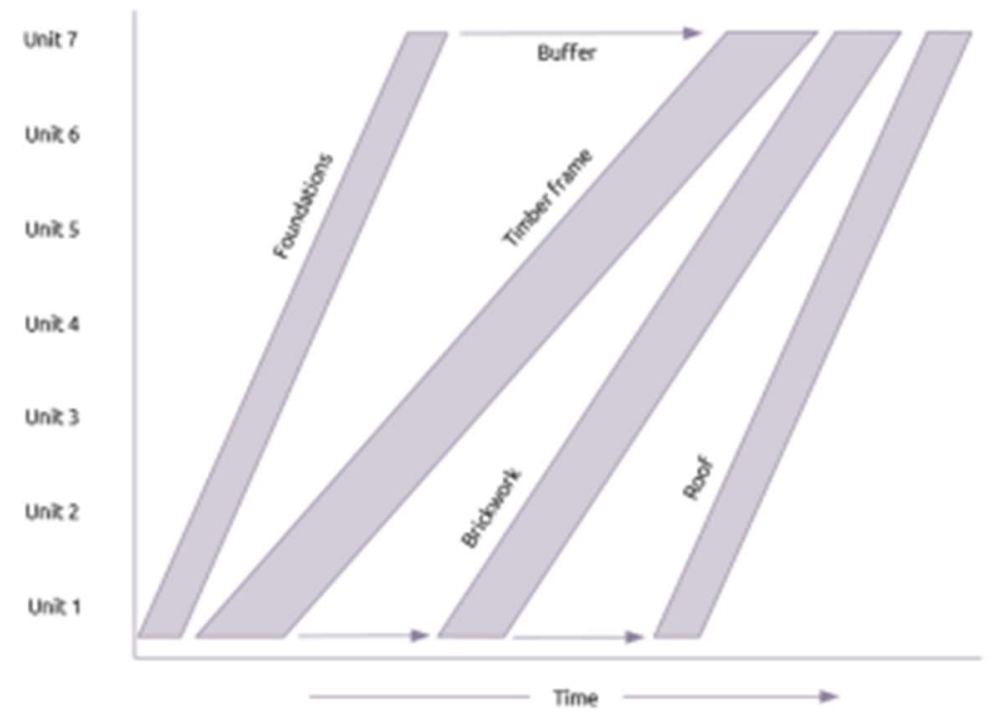

Figure 5.6: A modified version of figure 5.5

Source: Praxis (2015) 
The modified version is such that the use of solid straight lines make it easier to show how each team would work at a different speed. The steepness indicates the speed at which the teams move between the residential units. "The start of each trade is scheduled so that the work is completed as soon as possible with each trade having continuity of work. Natural buffers occur at the beginning or end of the trades work" (Praxis, 2015).

There are also instances where the Line of Balance diagrams are refered to as a "time chainage chart" where the diagram is combined with the architectural layouts of the project on the y-axis as shown in figure 5.7.

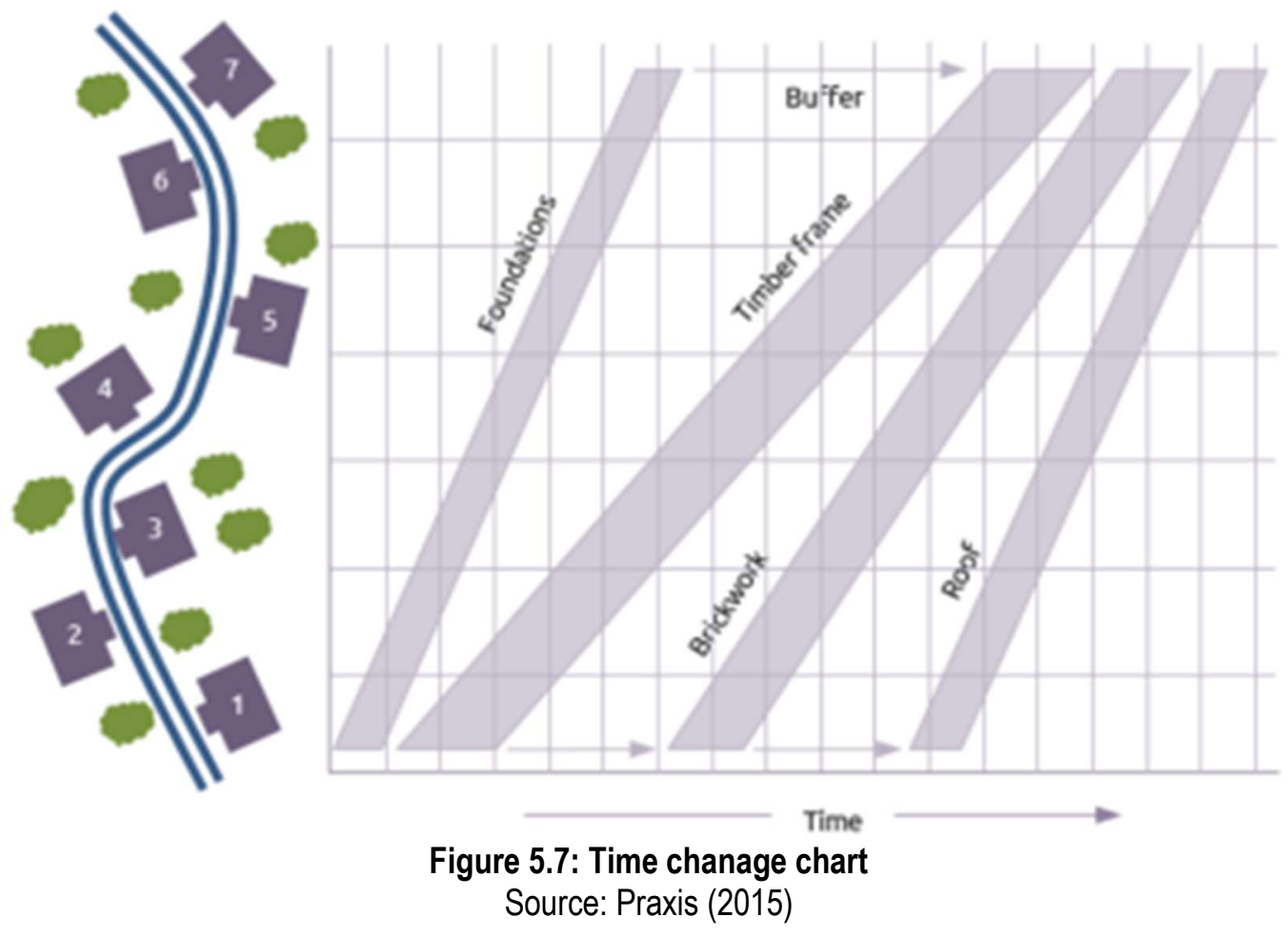

Line of Balance diagrams allow for a better understanding of the quantity of work to be done at a specific time and place. It also ensures the optimization of resources for a greater amount of activities that are repeated. Due to the availability of information for each activity, Line of Balance diagrams also makes the analysis of time and cost optimization analysis easier. Furthermore, modifying and updating a Line of Balance diagram is also relatively easy (Designing Buildings Wiki, 2017; Praxis, 2015). One disadvantage of Line of Balance diagrams is that it does not account for delays in progress and the ripple effects, hence where this occurs, it is represented with an intersection as shown in figure 5.8 . 


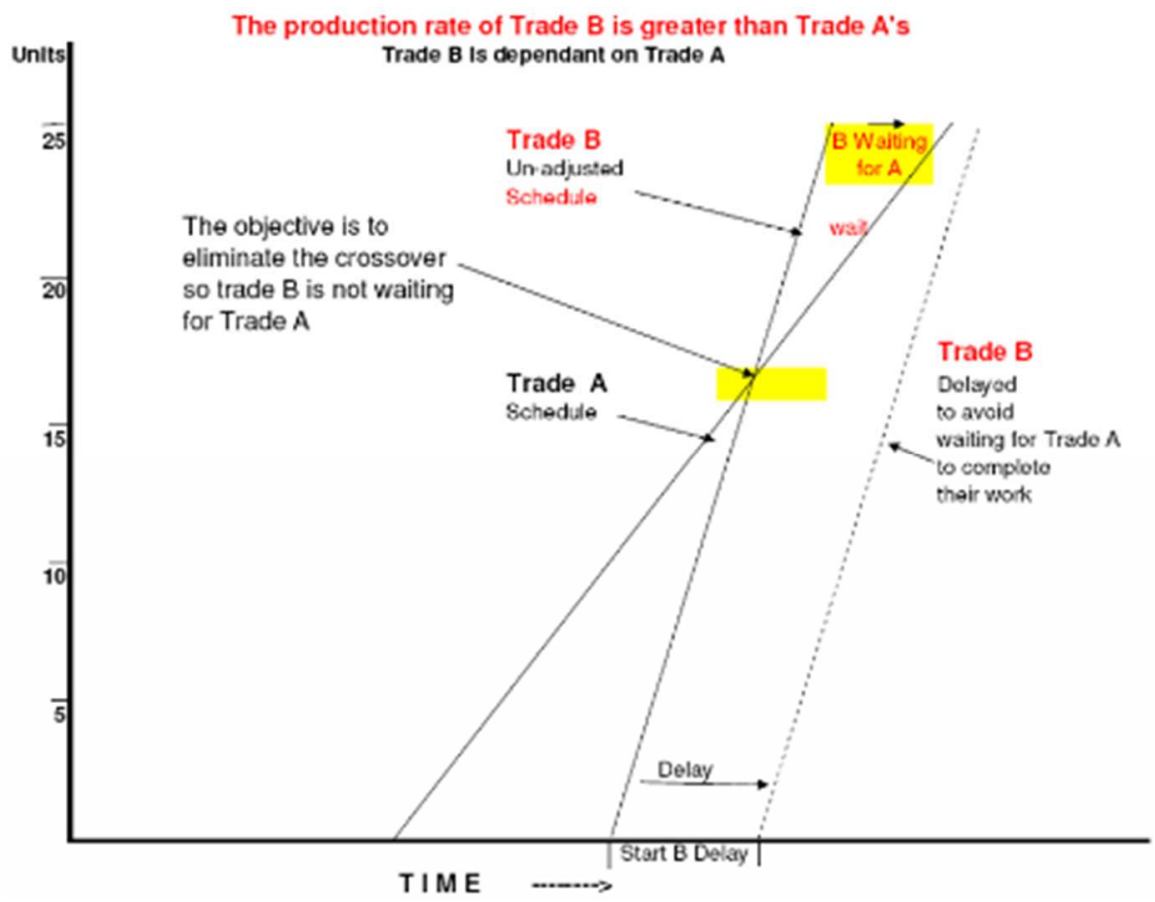

Figure 5.8: A Line of Balance diagram showing an intersection due to

Source: Mosaic Projects (2019)

Line of Balance diagrams also tend to become difficult to read and very complicated for much larger projects as shown figure 5.9 below.

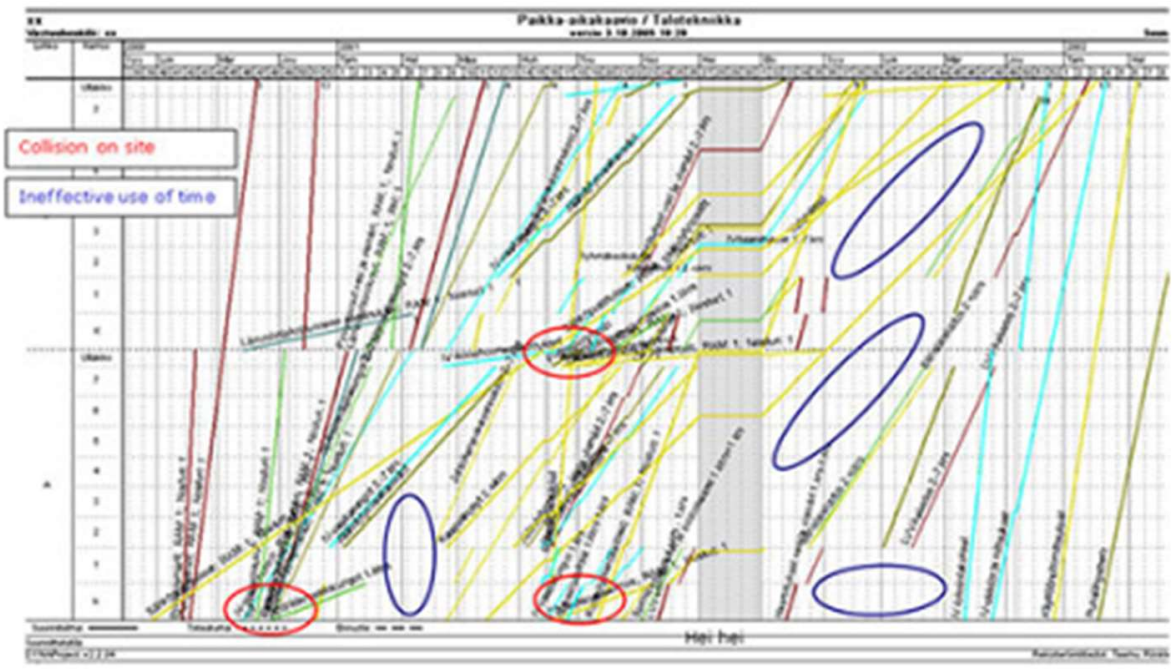

Figure 5.9: A Line of Balance diagram for a more complex project

Source: Mosaic Projects (2019) 


\subsection{Network Scheduling}

Due to the ever-increasing complexities, deadlines and amounts of data, there has been a need for better ways to control and manage projects in the construction industry that is highly competitive. Network scheduling techniques serve as a means to achieve (Kerzner, 2009)

\subsubsection{Critical Path Method (CPM)}

According to Kerzner (2009), a critical path is "that sequence of activities and events whose accomplishment will require the greatest time." This is a technique that the construction industry has benefited from in areas such as the project planning, project control, communication of plans and training of new project managers (Castro-Lacouture, Süer, Gonzalez-Joaqui \& Yates, 2009). It has been in use since the mid-20th century. Also known as the Arrow Diagram Method (ADM), it was created by the DuPont Company to improve the planning and development process of their projects by identifying the critical activities within a network of activities in a project. The Critical Path Method has the main goal of optimizing the compromise between the duration and the costs of projects. According to Ruina (2015), the essential requirements to create a CPM diagram include the following:
i. $\quad$ A list of the activities that are needed to complete the project;
ii. Dependencies between the activities;
iii. Duration of each activity.

The compromise between time and cost of a project in CPM is represented by the tradeoff graph as shown in figure 5.10 .

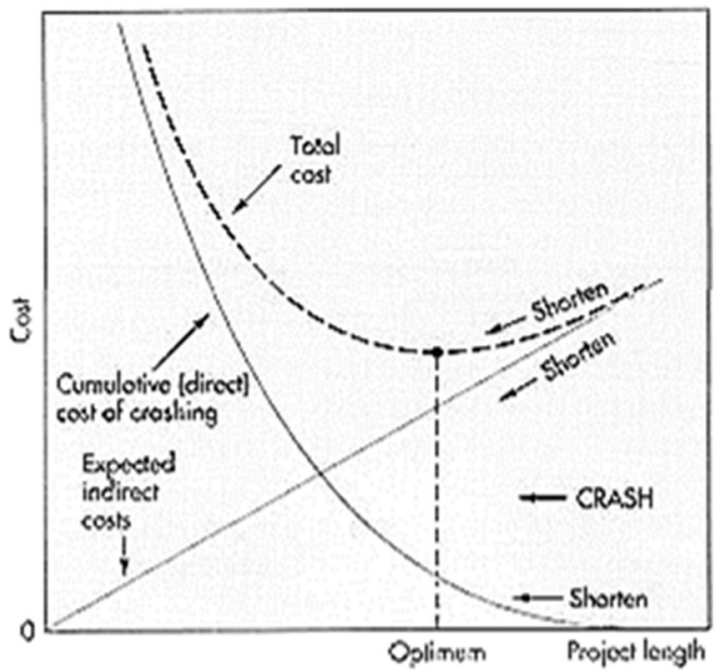

\begin{abstract}
"If the project has to be completed in a really short time, the total cost (dotted line) is extremely high whereas if there is more time to finish the project, the cost decreases (see dotted line)." "Conversely, if the project is behind schedule, there are going to be drawbacks." "Therefore, the total cost line increases again. The dotted line is the sum of direct costs and indirect costs" (Ruina, 2015; Kerzner, 2009).
\end{abstract}

TOTAL COST = DIRECT COSTS + INDIRECT COST

Figure 5.10: Time-cost tradeoff diagram

Source: Ruina (2015)

\subsubsection{Program Evaluation and Review Technique (PERT)}

This is a scheduling technique that is graphical in nature. It is used to show the timeline of the project. Developed by the United Stated Navy in the late 1950s due to the need to meet the requirements for more complex engineering projects, it was used for the Polaris submarine missile program. PERT has since that time spread rapidly throughout all industries. 
A typical PERT diagram is made up of the following:

i. Individual activities that make up the whole project must be clear enough to be put in a network.

ii. There must be a connection between the different activities. This can be done as shown in figure 5.11.
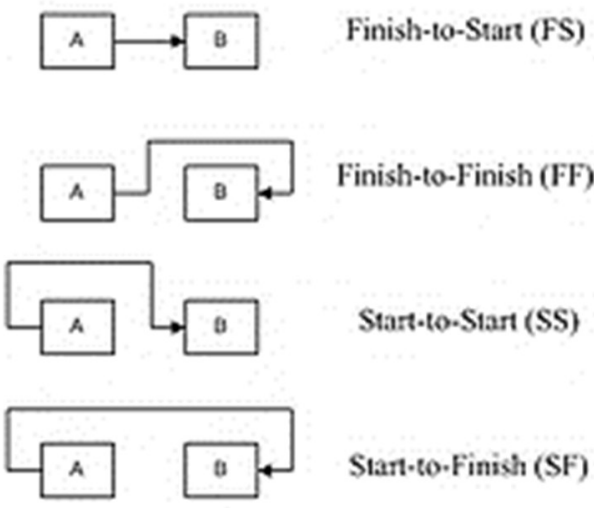

Figure 5.11: Relationship types

Source: Ruina (2015)

iii. Some activities need preset dates due to their impact on other activities.

iv. Working days, holidays and weekends need to be accounted for to make for the most accurate schedule possible.

V.

Time Estimations in PERT

Time estimates in PERT must be made for each activity on a three-way basis. There is a time estimation calculation to determine each activity's expected time (TE).

$$
\begin{gathered}
T E=\frac{O+4 M+P}{6} \quad \text { Variance }=\frac{(P-O)^{2}}{36} \\
\text { StandardDeviation }=\sqrt{\text { Variance }}
\end{gathered}
$$

Where;

$\mathrm{O}=$ optimistic time, $\mathrm{M}=$ medium (most likely) time and $\mathrm{P}=$ pessimistic time. This serves as the best way to get a more precise value for the duration of the project. Calculating the variance helps to determine the extent to which the project can be delayed or postponed based on the estimate. This is represented in a BETA distribution graph as shown in figure 5.12 (Kerzner, 2009; Ruina, 2015; Defense System Management College, 2001). 


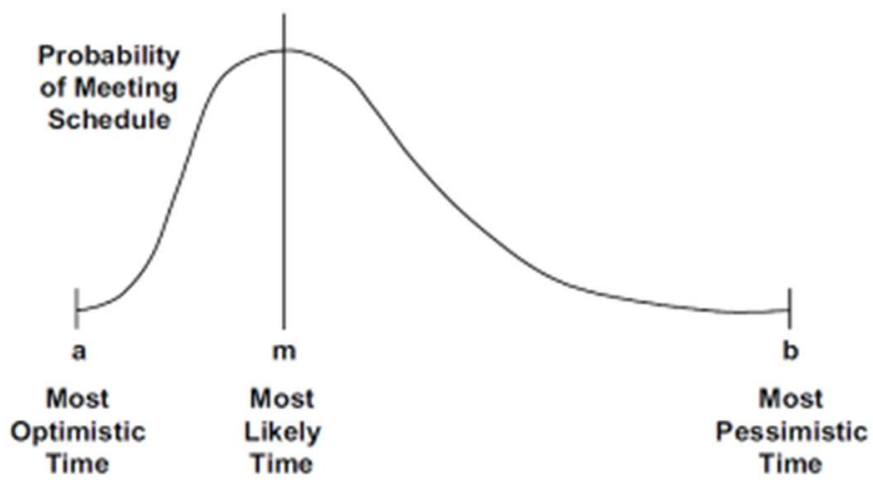

Figure 5.12: A BETA distribution graph

Source: Defense System Management College (2001)

"In spite of misuses that have occurred in PERT applications, the technique can be a very useful tool because it enables the manager to visualize the entire program, see interrelationships and dependencies, and recognize when delays are acceptable." This therefore enables the manager to make assessments on problems as the project progresses (Defense System Management College, 2001).

\subsubsection{Precedence Diagram Method (PDM)}

Also known as the activity-on-node (AON) method, PDM is a scheduling technique that uses a network diagram with boxes (nodes) that represent activities and makes connections with arrows that shows dependencies as shown in figure 5.13. It was developed in the 1960s by H. B. Zachary with the help of the IBM Corporation (Better Projects, 2005; Hiệu, 2016; Defense System Management College, 2001).

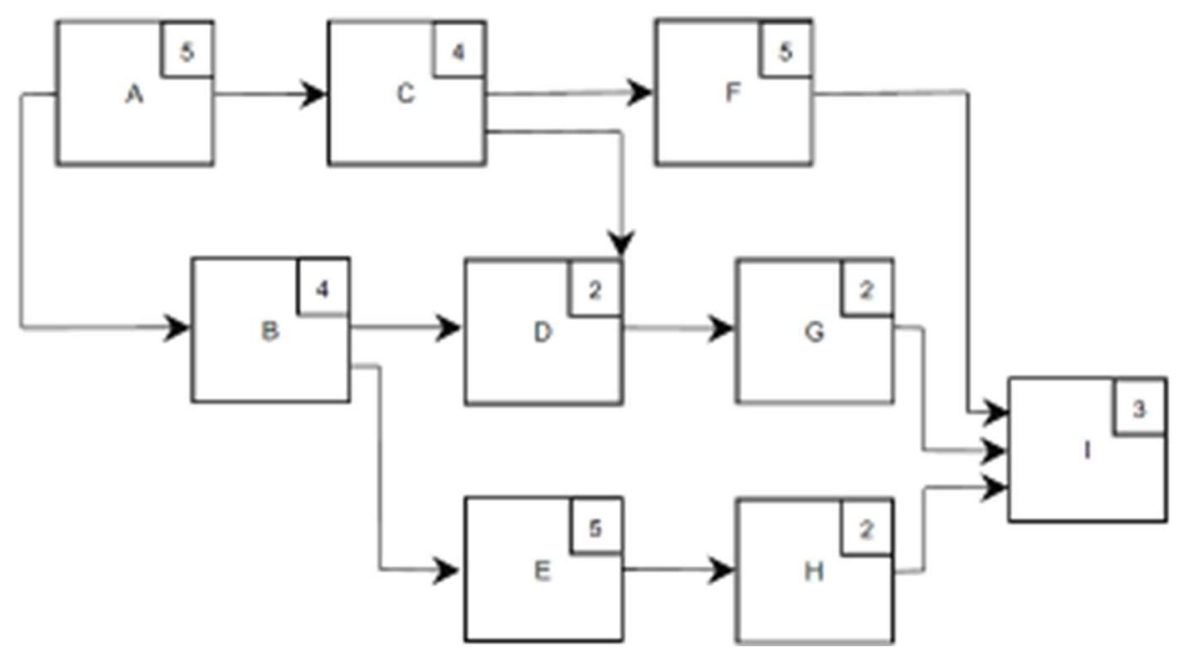

Figure 5.13: A PDM diagram

Source: Defense System Management College (2001) 
The key elements that are fundamental to a PDM node are represented in figure 5.14 below.

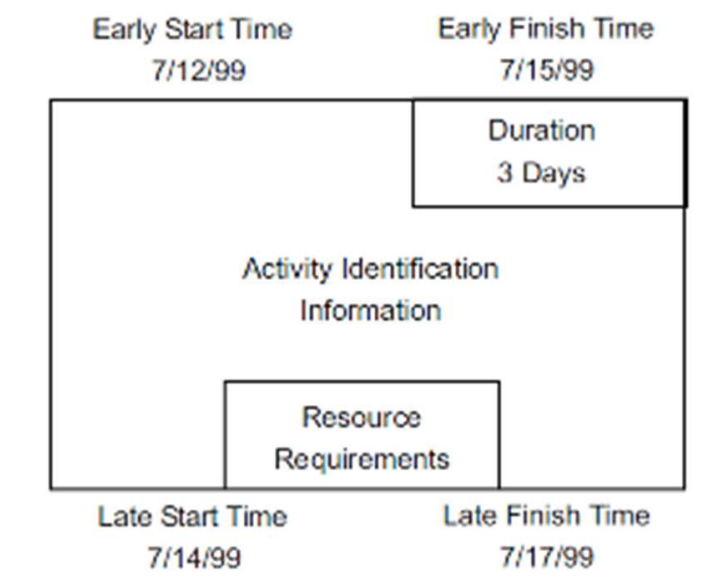

Figure 5.14: A PDM node

Source: Defense System Management College (2001)

PDM is a scheduling technique that is mostly computerized in nature and this is due to the ease to which printers and plotters produced the diagrams. PDM also uses the same underlying principles as the other networking techniques (Kerzner, 2009; Defense System Management College, 2001).

\subsubsection{Graphical Evaluation and Review Techniques (GERT)}

As introduced first by Dr. Alan B. Pritsker in 1966, GERT is a scheduling method which uses network analysis that treats time estimates and network logic probabilistically. It is not commonly used in complex projects but it addresses most of the limitations of CPM and PERT. The main disadvantage is that it requires a complex program to be utilized (Pritsker, 1979).

\subsubsection{Advantages of Network Scheduling}

Network scheduling techniques help management teams make decisions on time and cost-efficient resource utilization thereby forming the basis for all planning and predicting. They also help organize what would otherwise be confusing material, making it easier for managers to make tradeoffs and develop alternative plans. Furthermore, network scheduling techniques force communications among team members in identifying activities. They also allow managers to predict resource shortages and act on them early. Simulation of scenarios in "what if" impact exercises are also allowed with these techniques. These techniques also provide the basis for Gantt and milestone chart information (Borysowich, 2008; Defense System Management College, 2001; Kerzner, 2009).

\subsubsection{Disadvantages of Network Scheduling}

The network construction that these techniques demand can be difficult and time consuming. These methods are only as comprehensive as the activity time and resource estimates. They are sometimes difficult to portray graphically - too many lines, nodes and intersections. Furthermore, network scheduling techniques are not particularly good for conveying information in briefings/reviews. Complex networks, once sketched out on a large wall chart, tend to become the focus of management attention when, in fact, a manager should be paying attention to factors not on the chart, such as management/labor relations (Defense System Management College, 2001; Kerzner, 2009; Borysowich, 2008). 


\subsection{Benefits of Scheduling Techniques for Construction Projects}

Managing a project efficiently and effectively means taking advantage of scheduling tools and techniques to use resources optimally. It is fundamental to use scheduling techniques to reduces as much as possible their impact on a bigger scale. According to Fournier (2015), there are various benefits of making use of these scheduling techniques before the comencement of a construction project. They are as listed below.

i. They ensure that the need to pre-plan the project brings about the creation of information of the specifics and less surprises well into the project.

ii. $\quad$ Scheduling improves the planning of essential resources such as labor and equipment.

iii. Scheduling also makes the most of quality control procedures by properly sequencing the work.

iv. Scheduling techniques ensure that materials and critical elements are purchased with enough lead time while also enhancing coordination efforts between client and construction operations

v. Scheduling techniques give the affected parties such as the subs, vendors, designers and client time to better plan their own activities

vi. Submitting shop drawings, samples and data sheets in timely fashion

vii. Reducing risk of damage to adjacent property and installed work leading to a reduced punch list

viii. Improving safety performance by sequencing the activities to ensure maximum protection for workers

ix. Achieving the highest level of productivity in order to complete the project in the shortest timeframe reasonably possible

$\mathrm{x}$. Pricing winter protection measures accurately by knowing which weather sensitive activities will be put in place during cold weather and the duration of those activities

\section{CONCLUDING REMARKS}

"The Construction Industry Institute (CII) conducted a study and found that a positive, quantifiable relationship exists between the effort expended during the pre-project planning phase and the ultimate success of a project" (Fournier, 2015). Project scheduling seeks to provide various benefits to building construction project managers and stakeholders. Resource (time and cost) efficiency, minimized risk, ease of progress assessment and control and ease of communication are just some of the benefits that project scheduling provides. 


\section{REFERENCES}

1. Better Projects. (2005, October 12). PDMs - Precedence Diagram Method. Retrieved April 6, 2019, from Better Projects: http://www.betterprojects.net/2005/10/pdms-precedence-diagram-method.html

2. Borysowich, C. (2008, February 2). Pros \& Cons of the PERT/CPM Method. (Ziff Davis, LLC) Retrieved April 6, 2019, from ToolBox: https://it.toolbox.com/blogs/craigborysowich/pros-cons-of-the-pert-cpm-method020108

3. Castro-Lacouture, D., Süer, G. A., Gonzalez-Joaqui, J., \& Yates, J. K. (2009, October 1). Construction Project Scheduling with Time, Cost,. Journal of Construction Engineering and Management and Material Restrictions Using Fuzzy Mathematical Models and Critical Path Method, 135(10), 1096-1104. doi:10.1061/135

4. Defense System Management College. (2001). Scheduling Guide for Program Managers. (W. W. Bahnmaier, Ed.) Fort Belvoir, VA: Defense Systems Management College Press. Retrieved from http://www.acqnotes.com/Attachments/Scheduling $\% 20$ Guide $\% 20$ for $\% 20$ Program $\% 20$ Managers $\% 200 c t \% 2$ 02001.pdf

5. Designing Buildings Wiki. (2017, February 24). Line of balance (LOB). (Designing Buildings Ltd.) Retrieved April 5, 2019, from Designing Buildings Wiki: https://www.designingbuildings.co.uk/wiki/Line_of_balance_(LOB)

6. Fournier, N. (2015, June 3). 11 Benefits of Creating a Construction Schedule before Work Starts. (SoSimple) Retrieved April 5, 2019, from C.E. Floyd Company: https://cefloyd.com/our-blog?id=70242/11benefits-of-creating-a-construction-schedule-before-work-starts

7. Gantt.com. (2019). What is a Gantt Chart? Retrieved April 3, 2019, from Gantt.com: https://www.gantt.com/

8. Ghaeli, M. .., \& Sadi-Nezhad, S. (2019, January 23). A Scientometrics Survey on Project Scheduling. Journal of Project Management, 165-176. doi:10.5267/j.jpm.2019.1.006

9. Hiệu, D. (2016, September 26). Precedence diagram method. (Wikimedia Foundation, Inc.) Retrieved April 7, 2019, from Wikipedia, the free encyclopedia: https://en.wikipedia.org/wiki/Precedence_diagram_method

10. Kerzner, H. R. (2009). Project Management: A Systems Approach to Planning, Scheduling, and Controlling (10th ed.). Online: John Wiley \& Sons. Retrieved April 5, 2019, from https://www.oreilly.com/library/view/project-management-a/9780470278703/

11. Manning, B. (2018, June 6). Line of Balance (LOB). Retrieved April 4, 2019, from AcqNotes - Defense Acquisitions Made Easy: http://acqnotes.com/acqnote/tasks/line-of-balance

12. Manning, B. (2018, June 20). Milestone Chart. Retrieved April 4, 2019, from AcqNotes - Defense Acquisitions Made Easy: http://acqnotes.com/acqnote/tasks/milestone-chart

13. Mishra, G. (2018). Planning, Scheduling in Construction Management. Retrieved February 20, 2019, from The Constructor - Civil Engineering Home: https://theconstructor.org/construction/

14. Mosaic Projects. (2019). Scheduling Methodologies and Approaches - Line of Balance. Retrieved April 5, 2019, from Project Management Knowledge Index: https://mosaicprojects.com.au/WhitePapers/WP1021_LOB.pdf

15. Praxis. (2015). Line of balance. (Praxis Framework Limited) Retrieved April 5, 2019, from Praxis Framework: https://www.praxisframework.org/en/library/line-of-balance

16. Pritsker, A. B. (1979). Modeling and Analysis Using Q-GERT Networks (2nd ed.). Wiley. Retrieved April 7 , 2019, from http://www.rand.org/content/dam/rand/pubs/research_memoranda/2006/RM4973.pdf

17. Project-Management.com . (2018, October 10). Advantages and Disadvantages of Gantt Charts. Retrieved April 4, 2019, from Project-Management.com : https://project-management.com/advantages-anddisadvantages-of-gantt-charts/ 
18. ProjectManager.com Inc. (2019). The Ultimate Guide to Gantt Charts. Retrieved April 3, 2019, from ProjectManager: https://www.projectmanager.com/gantt-chart

19. Ruina, J. L. (2015). Scheduling techniques in Project Management. (MediaWiki) Retrieved February 25, 2019, from http://apppm.man.dtu.dk: http://apppm.man.dtu.dk/index.php/Scheduling_techniques_in_Project_Management

20. Ssempebwa, R. K. (2013). Project Schedule Management. Atlanta International University. Atlanta: ResearchGate (Online). Retrieved March 13, 2019, from https://www.researchgate.net/publication/273759807

21. TeamGantt. (2019). What is a Gantt Chart? Gantt Definitions \& Uses. Retrieved April 3, 2019, from TeamGantt: https://www.teamgantt.com/what-is-a-gantt-chart

22. Valuation Opinions, Inc. (2018). Line of Balance. (Valuation Opinions, Inc.) Retrieved April 5, 2019, from Valuation Opinions, Inc.: http://www.valuation-opinions.com/ev/lob.lasso

23. Van Dyke, S. (2019). Residential Construction Project Schedule Template. Retrieved February 22, 2019, from ShawnVanDyke.com: http://ShawnVanDyke.com/RESIDENTIAL-CONSTRUCTION-PROJECTSCHEDULE-TEMPLATE 